\title{
Lung Micropapillary Adenocarcinoma
}

National Cancer Institute

\section{Source}

National Cancer Institute. Lung Micropapillary Adenocarcinoma. NCI Thesaurus. Code C128847.

An aggressive variant of lung adenocarcinoma that exhibits a micropapillary architectural pattern. The prognosis is usually poor. 